Archived version from NCDOCKS Institutional Repository http://libres.uncg.edu/ir/asu/

Whitehead, John C., Ben Poulter, Okmyung Bin and Christopher F. Dumas. (2009). Measuring the Economic Effects of Sea-Level Rise on Shore Fishing. Mitigation and Adaptation Strategies for Global Change, 14(8):777-792. Publisher's version available from www.springer.com (ISSN: 1381-2386) (DOI: 10.1007/s11027-009-9198-1)

\title{
Measuring the economic effects of sea level rise on shore fishing
}

John C. Whitehead \& Ben Poulter \& Christopher F. Dumas \& Okmyung Bin

\begin{abstract}
In this paper we develop estimates of the economic effects of sea level rise on marine recreational shore fishing in North Carolina, USA. The relationship between angler behavior and spatial differences in beach width is estimated using the Marine Recreational Fishing Statistics Survey and geospatial data. We exploit the empirical relationship between beach width and fishing site choice by simulating the effects of sea level rise on angler site choice. We find that reductions in beach width negatively affect the quality and number of fishing trips even as anglers adapt by using piers and bridges. Welfare losses are potentially substantial, ranging up 39\% of the total value of marine shore fishing in North Carolina.
\end{abstract}

Keywords Economic benefits . Marine recreational fishing . Travel cost method . Climate change. Sea level rise 


\section{Introduction}

Rapid economic growth in the coastal zone in the last few decades has resulted in denser populations and more valuable coastal property. However, coastal development is exposed to considerable risk as sea level is projected to rise by at least 0.18 to 0.59 $\mathrm{m}$ over the next century (Intergovernmental Panel on Climate Change 2007) creating potential problems for coastal economies. North Carolina is particularly vulnerable economically to sea level rise. Coastal North Carolina is located within the relatively low-income eastern region of the state and the coastal tourism market is an important economic sector in this region. Given that the barrier island roads and highways act as barricades in the absence of a beach retreat policy, sea-level rise and its effect on coastal erosion is expected to result in significant changes in beach width impacting the land that currently hosts beach cottages and beach tourism opportunities.

In this study, we estimate the impacts of sea level rise on marine recreational shore fishing in North Carolina. Assessment of the non-market effects of climate change mitigation policy (e.g., recreational fishing impacts) is important because estimates of the market effects of policy are relatively abundant (Mendelsohn and Neumann 1999). The market effects can be measured with observable parts of the economy (e.g., changes in market prices and quantities). The nonmarket effects of climate change policy often only indirectly affect market prices and quantities or occur outside of markets entirely. Often, the market effects of policy seem certain next to nonmarket effects. The monetary value of market effects is given more weight in benefit-cost analysis and the net benefits of climate policy can be biased downward. Measurement of nonmarket effects is important to avoid this bias.

The concept of consumer surplus is the basis for the theoretical definition of the economic benefits of climate change mitigation policy. Consumer surplus is the difference between what the consumer is willing to pay and the market price or cost of the product. Consumer surplus is also called net willingness to pay since it is willingness to pay net of the costs. In the case of marine recreational fishing, if the angler is willing to pay $\$ 100$ for a fishing trip and the out-of-pocket expenditures are $\$ 25$ then the consumer surplus is $\$ 75$. The consumer surplus is the value of the recreation experience to the recreationist, while the out-of-pocket expenditures represent the initial, direct economic impact of the trip on the regional and local beach economies. Hereafter, we refer to consumer surplus as willingness to pay, or WTP.

Estimation of WTP from demand curves is relatively straightforward if market data exists. Without market data, a number of methodologies have been developed to estimate WTP for environmental, and other, non-market goods. The travel cost method is a revealed preference approach that is most often used to estimate the benefits of outdoor recreation. The travel cost method begins with the insight that the major cost of outdoor recreation is the travel and time costs incurred to get to the recreation site (Smith and Kaoru 1990). Since individuals reside at varying distances from the recreation site, the variation in distance and the number of trips taken are used to estimate a demand curve for the recreation site. The demand curve can then be used to 
derive the WTP associated with using the site. With data on appropriate demand curve shift variables (i.e., independent variables such as beach width), the economic benefits (i.e., changes in WTP) associated with changes in the shift variables can be derived.

Past research on the impact of climate change on outdoor recreational activities in the United States is sparse. Early studies found that precipitation and temperature affects beach recreation activities (McConnell 1977; Silberman and Klock 1988). More recently, Englin and Moeltner (2004) found that temperature and precipitation affect the number of skiing and snowboarding days in expected ways.

Two studies have related the effects of temperature and precipitation on outdoor recreation activities and used these results to model the impacts on WTP of climate change on the entire United States. That research found that the impacts of climate change on outdoor recreation are likely to be positive. Mendelsohn and Markowski (1999) considered the effects of changes in temperature and precipitation on boating, camping, fishing, hunting, skiing and wildlife viewing using statewide aggregate demand functions. Considering a range of climate scenarios, the authors found that increased temperature and precipitation increase the aggregate WTP of hunting, freshwater fishing and boating and decrease the aggregate WTP of camping, skiing and wildlife viewing. The net impacts of climate change on aggregate WTP were positive.

Loomis and Crespi (1999) took an approach similar to Mendelsohn and Markowski (1999) but used microdata. They considered the effects of temperature and precipitation on beach recreation, reservoir recreation, stream recreation, downhill and cross-country skiing, waterfowl hunting, bird viewing and forest recreation. Overall, they found that climate change is likely to have positive impacts on the aggregate WTP of outdoor recreation activities. Of interest to this study, they considered the impacts of sea level rise on beach recreation and waterfowl hunting. For beach recreation they used the positive relationship between beach length and the number of beach days per month to assess the loss of beaches. The joint effects of increased temperature, increased precipitation and beach loss led to positive economic impact. For waterfowl hunting they used the relationship between wetland acres and waterfowl hunting participation and found a negative economic impact with sea level rise.

Three studies have focused on more narrow regions and outdoor recreational activities. Pendleton and Mendelsohn (1998) related the effects of temperature and precipitation to catch rates for trout and pan fish in the northeastern United States. Climate change is expected to decrease trout catch rates and increase pan fish catch rates. Using recreation demand models and microdata, the authors found that fish catch rates influence fishing site location choice. Combining the effects of climate change on catch rates the authors found that climate change would, in general, benefit freshwater fishing in the northeastern United States. Ahn et al. (2000) focused on trout fishing in the Southern Appalachian Mountain region of North Carolina. Using methods similar to Pendleton and Mendelsohn (1998) the authors found contrasting results. Based on their results climate change would reduce the welfare of trout anglers in this region. The 
contrast may be due to a lack of species substitution possibilities (e.g., pan fish) in Ahn et al.'s demand model.

Richardson and Loomis (2004) provided an additional contrast by employing a stated preference approach to estimate the impacts of climate change on WTP for recreation at Rocky Mountain National Park. In this context, stated preference surveys ask outdoor recreation participants for their willingness to pay to prevent climate change or for their hypothetical changes in visitation behavior with changes in climate. Richardson and Loomis' hypothetical scenario explicitly considered the direct effects of climate, temperature and precipitation, and the indirect effects of temperature and precipitation on other environmental factors such as vegetation composition and wildlife populations. Using visitor data, they found that climate would have positive impacts on visitation at Rocky Mountain National Park.

To estimate recreational impacts from sea level rise on marine recreational shore fishing, we follow the methods employed in previous revealed preference, climate change, microdata, recreation demand studies as described by Shaw and Loomis (2008). Considering the conceptual framework developed by Shaw and Loomis (2008), we estimate the relationship between indirect effects of climate change (e.g., beach width) and effects on outdoor recreation and benefits. We exploit the relationship between existing beach width and fishing trips and simulate (1) the effects of sea level rise and coastal erosion on beach width and (2) the effects of beach width on angling behavior. Due to data limitations, we do not consider direct effects of climate change (e.g., temperature, precipitation and climate variability) or other indirect effects of climate change (e.g., fish stocks and composition) on angler trips.

In particular, we use the random utility model version of the revealed preference travel cost method (Haab and McConnell 2002). In this model, it is assumed that individuals choose recreation sites based on tradeoffs among trip costs and site characteristics (e.g., beach width, catch rates). Beach width might affect angling decisions in North Carolina due to the complementary between the use of beach buggies (i.e., four wheel drive trucks and sport utility vehicles) and beach site access. Narrow beaches do not support the transportation of gear and anglers to fishing sites. If anglers make fishing site selections based on beach width, then the existing relationship between variation in beach width and fishing site selection can be used to simulate the impact of an eroded beach. We calculate current erosion rates for fishing locations and model projected beach widths with geospatial data. Projected increases in beach erosion are estimated for the years 2030 and 2080. Increased shoreline erosion is anticipated because of increased storminess and changes in shoreline geometry from sea level rise (Crowell et al. 1997, Zhang et al. 2004). These erosion rates are then mapped spatially to describe changes in beach width assuming no beach nourishment, barrier island migration or beach retreat.

In the rest of this paper, we describe the methods used to measure the impacts of sea level rise on beach width. We describe the angler data and the empirical model. The empirical results are presented and willingness to pay values are derived. The potential 
impacts of sea level rise on angler activity are estimated and policy implications are discussed.

\section{Geospatial Analysis}

Twenty-eight shore fishing locations were identified from the fishing data described below (Fig. 1). The first line of stable natural vegetation on the beach (i.e., vegetation line) for each location was digitized for approximately $1-3 \mathrm{~km}$ in either direction of the fishing location (initially identified as a lat/long point) using 2005 USDA National Air Inventory Program photographs. The $1-3 \mathrm{~km}$ beach length was selected to reduce bias from local erosion rates and present a more integrated beach erosion rate. Beach width was calculated by measuring the distance between the vegetation line and a vectorized 1998 shoreline provided by the North Carolina Division of Coastal Management.

To calculate the erosion rate for each beach, we used erosion rate transect data provided by the U.S. Geological Survey (Fig. 2) and georeferenced to the same coordinate system as the beach width analysis (North Carolina, Stateplane coordinates). These data consist of short-term (1970-1997) and long-term (1849-1997) erosion data measured directly from aerial photograph time sequences. Each transect extends from the ocean toward the estuary and has attributes describing erosion. A series of these transects runs north to south and captures any spatial variation in the rates of erosion that exist along the shoreline. Transects (separated by approximately $100 \mathrm{~m}$ ) were intersected with the vegetation line for a beach to obtain erosion rates. The erosion attributes for each transect were then aggregated for each beach (i.e., the 1-3 $\mathrm{km}$ beachfront) to provide a range of erosion estimates summarized to mean, minimum, maximum, and standard deviation. Projected changes in beach width were then calculated for the years 2030 and 2080 using percent increase factors applied to current shoreline erosion rates (Table 1, personal communication, Orrin Pilkey).

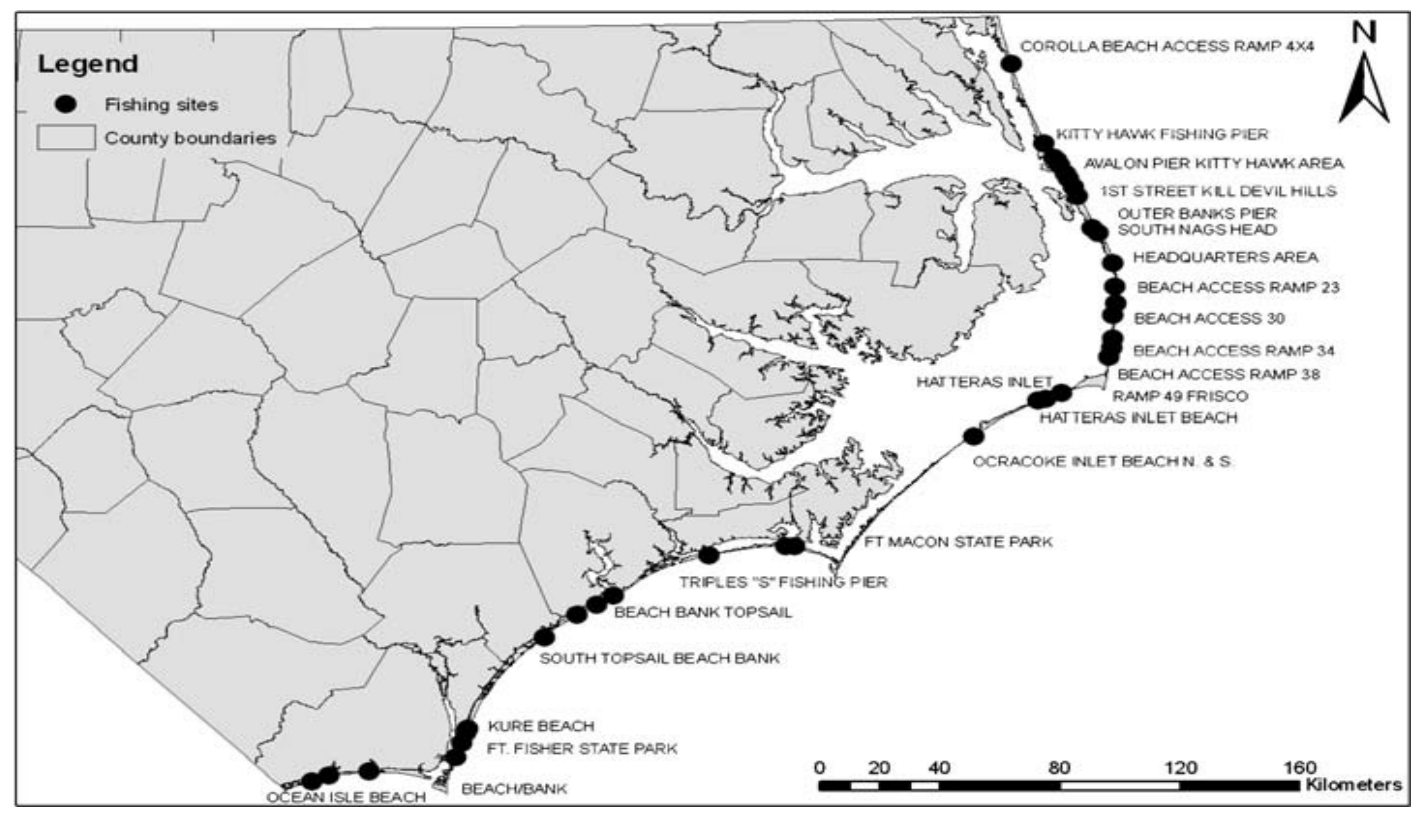

Fig. 1 Location of fishing beaches 
An important assumption is the lack of adaptation in terms of beach nourishment. Each of the beaches that we consider is bordered inland by highways and roads. We assume that beach erosion proceeds to the highway or road and, at that point, the sandy beach has vanished. This is the most extreme assumption but it allows us to estimate of the maximum

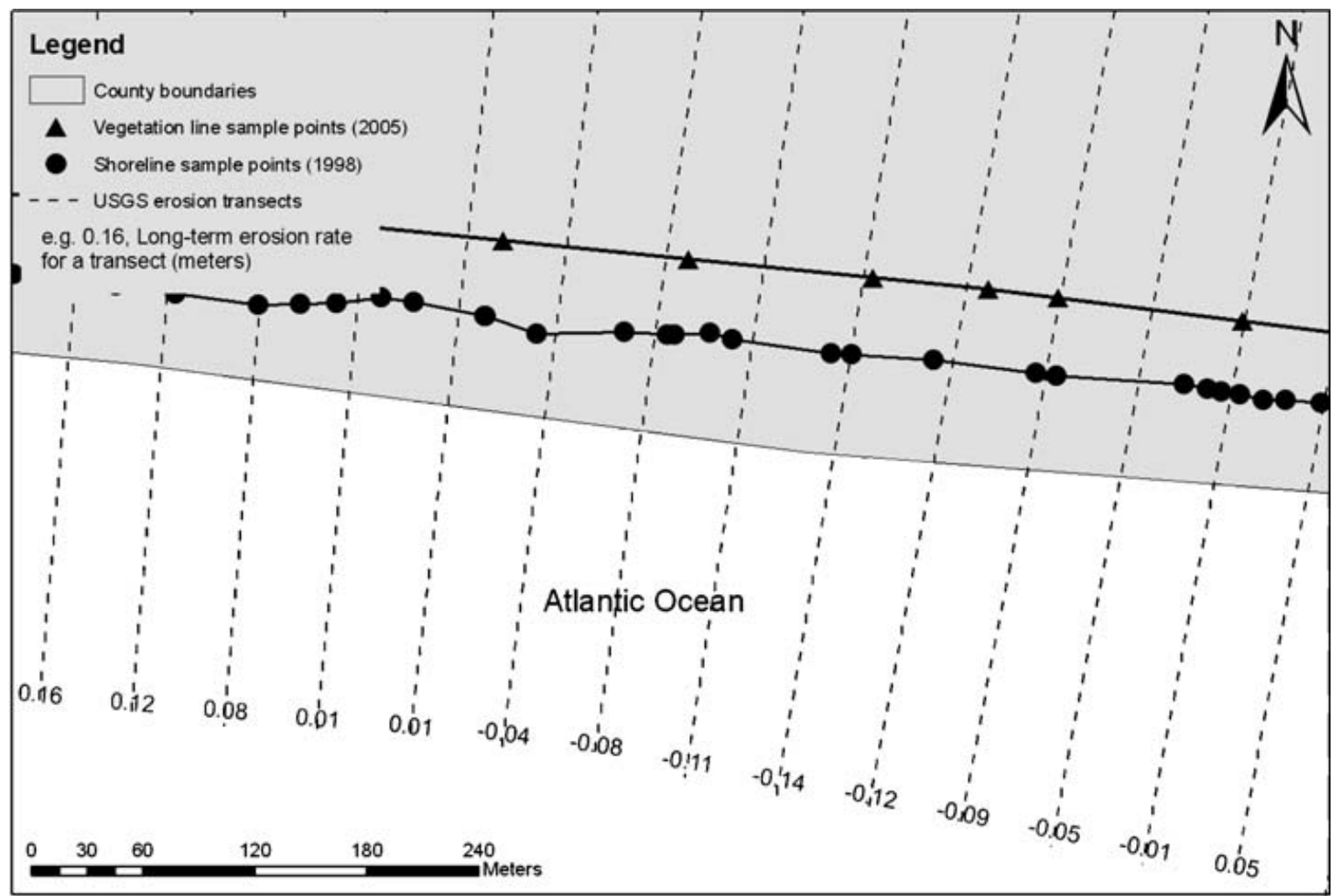

Fig. 2 Illustration of calculation of erosion rates for fishing beaches 
Table 1 Mean current and projected beach widths

\begin{tabular}{|c|c|c|c|c|c|}
\hline Choice & Site Name & County & 2005 & 2030 & 2080 \\
\hline 1 & Oregon Inlet South & Dare & 27.17 & -4.34 & -9.59 \\
\hline 2 & Cape Point & Dare & 46.88 & 15.37 & 10.12 \\
\hline 3 & Hatteras Inlet & Dare & 39.11 & 7.60 & 2.34 \\
\hline 4 & Kure Beach & New Hanover & 211.47 & 179.95 & 174.70 \\
\hline 5 & Holden Beach & Brunswick & 225.65 & 194.14 & 188.88 \\
\hline 6 & Ft Fisher State Beach & New Hanover & 225.65 & 194.14 & 188.88 \\
\hline 7 & Ocracoke Inlet Beach N. \& S. & Hyde & 36.51 & 5.00 & -0.25 \\
\hline 8 & Avalon Pier Kitty Hawk Area & Dare & 310.36 & 278.84 & 273.59 \\
\hline 9 & Ft Macon State Park & Carteret & 81.31 & 49.80 & 44.55 \\
\hline 10 & Emerald Isle Public Access Area & Carteret & 84.87 & 53.35 & 48.10 \\
\hline 11 & Oregon Inlet North Shore & Dare & 59.53 & 28.02 & 22.77 \\
\hline 12 & Hatteras Inlet Beach & Hyde & 83.26 & 51.75 & 46.49 \\
\hline 13 & Access at New River Inlet Drive & Onslow & 94.83 & 63.32 & 58.07 \\
\hline 14 & Beach Access Ramp 20 & Dare & 82.32 & 50.80 & 45.55 \\
\hline 15 & Beach Access Ramp 23 & Dare & 49.87 & 18.36 & 13.10 \\
\hline 16 & Beach Access 27 & Dare & 60.12 & 28.61 & 23.36 \\
\hline 17 & Beach Access 30 & Dare & 45.02 & 13.51 & 8.26 \\
\hline 18 & Beach Access Ramp 34 & Dare & 50.37 & 18.86 & 13.60 \\
\hline 19 & Beach Access Ramp 38 & Dare & 47.73 & 16.21 & 10.96 \\
\hline 20 & New River Inlet, Topsail Island & Onslow & 55.03 & 23.51 & 18.26 \\
\hline 21 & Carolina Beach NW Extension & New Hanover & 122.39 & 90.88 & 85.63 \\
\hline 22 & Calvin Street Kill Devil Hills & Dare & 276.45 & 244.93 & 239.68 \\
\hline 23 & 1st Street Kill Devil Hills & Dare & 77.36 & 45.85 & 40.60 \\
\hline 24 & Public Access E. Gulfstream S. Nags Head & Dare & 37.45 & 5.94 & 0.68 \\
\hline 25 & Public Access E. Bonnett St Nags Head & Dare & 144.28 & 112.77 & 107.51 \\
\hline 26 & Public Access E. Forest St Nagshead & Dare & 50.97 & 19.46 & 14.21 \\
\hline 27 & Ramp 49 Frisco & Dare & 60.87 & 29.36 & 24.11 \\
\hline 28 & South Topsail Beach Bank & Pender & 30.41 & -1.10 & -6.35 \\
\hline
\end{tabular}

loss of recreation values that might be expected from sea level rise. Periodic beach nourishment occur in North Carolina but these efforts are costly. Natural beach nourishment processes also occur but these are difficult to predict.

\section{Recreational fishing data}

The National Marine Fisheries Service (NMFS) collects recreational fishing data annually with its Marine Recreational Fishery Statistics Survey (MRFSS). The MRFSS is focused on estimation of angler catch (i.e., a creel survey) with information on fishing location, mode, target species, catch and harvest, and fishing days during the past 2- 
month and 12-month time periods. Periodically, the NMFS collects additional data from anglers with economic add-on surveys. In the southeast region, economic add-ons have taken place in 1997 and 2000. An expenditure add-on was conducted in 2006 (Gentner et al. 2001).

The MRFSS add-on surveys requests additional information so that the travel cost method can be employed with the intercept creel survey data. Key information collected is on single-day vs. multiple-day trips and if fishing is the primary purpose of the trip. The travel cost method typically employs only single-day fishing trips (i.e., trips in which the respondent did not spend any nights away from the permanent residence) because overnight trips may have multiple purposes (McConnell and Strand, 1999).

We investigated the potential of the 1997 and 2000 MRFSS add-on data to support a shore-based demand model for North Carolina. Unfortunately, too few cases exist for demand analysis. Instead, we adapt the most recently available MRFSS data from 2005 and 2006. Forty-five percent of the North Carolina anglers fish from the shore (including beach, bank, pier and bridge) and almost all of these shore anglers use hook and line gear. We consider only those anglers who fished in ocean waters (excluding the sounds of coastal North Carolina). In an attempt to focus on day trips with a primary purpose of fishing, we exclude North Carolina anglers who reside outside of North Carolina. In a further attempt to consider only day trip anglers, we exclude anglers who live more than 200 mi from any of the fishing sites. In 2005 and 2006, 1905 and 1699 angler trips are available for analysis, respectively. Sixty-two percent of the anglers fish from piers or bridges while the rest fish from the shore among 28 beach fishing sites (Table 2). In order to consider substitute fishing opportunities, we include 22 pier and bridge fishing sites (Table 3). Similar to shoreline hardening as an adaptive response to sea level rise by homeowners, pier and bridge fishing is an adaptive response to sea level rise by anglers. We assume that pier and bridge fishing is available for anglers if beach fishing becomes unavailable due to sea level rise.

To measure site characteristics in the standard NMFS demand model, Haab et al. (2000) measured the catch and keep rate with the 5-year historic targeted harvest of big game fish (e.g., tunas), bottom fish (e.g., spot, groupers), flat fish (e.g., flounders), and small game fish (e.g., mackerels). In contrast, we consider all targeted species in the catch rates for the North Carolina shore fishing model, because only $26 \%$ of anglers in our data target specific species (most others target "anything they can catch"). Of those that target species, the most popular are spot, flounder, kingfish, seatrout, bluefish, striped bass, Spanish mackerel, red drum and king mackerel. Three year targeted historic catch and keep rates per hour were calculated using MRFSS data at each of the sites to measure site quality. The average catch rate per hour across all trip choice occasions is 0.62 .

The round-trip travel cost is $p=(c \times d)+(\theta w \times[d / m p h])$ where $\mathrm{c}$ is cost per mile; $\mathrm{d}$ is round trip distance; $\theta$ is a fraction of the wage rate, $\mathrm{w}$; and $\mathrm{mph}$ is miles per hour. We choose values for these variables based on typical values used in the literature. However, note that our results may be sensitive to different assumptions. Travel 
distances and time between each survey respondent's home zip code and the zip code of the population center of each beach county, which places the angler in close proximity to the fishing sites, are calculated using the ZIPFIP correction for "great circle" distances (Hellerstein et al. 1993). Travel time is calculated by dividing distance by 50 mi per hour. The cost per mile used, $\$ 0.485$, is the Internal Revenue Service's allowable vehicle reimbursement rate enacted in September 2005 following the Hurricane Katrina gas price increase. Thirty-three percent of the wage rate is used to value leisure time for each respondent. The wage rate is measured as annual income divided by 2,000 work hours. In the standard NMFS travel cost methodology, a measure of time cost is collected in the add-on survey for anglers who forego wages during the trip. Since income is not available with the creel surveys, we use the zip-code level median household income from the 2000 Census, inflated to 2005 dollars using the consumer price index, as a proxy for household income in the measurement of the opportunity cost of time. The average travel cost across all trip choice occasions is $\$ 198$.

\section{Table 2 Beach and bank fishing site trip frequency}

\begin{tabular}{lllrl} 
Choice & Site Name & County & Frequency & Percent \\
\hline 1 & Oregon Inlet South & Dare & 49 & 1.36 \\
2 & Cape Point & Dare & 328 & 9.1 \\
3 & Hatteras Inlet & Dare & 54 & 1.5 \\
4 & Kure Beach & New Hanover & 44 & 1.22 \\
5 & Holden Beach & Brunswick & 17 & 0.47 \\
6 & Ft Fisher State Beach & New Hanover & 7 & 0.19 \\
7 & Ocracoke Inlet Beach N. \& S. & Hyde & 7 & 0.19 \\
8 & Avalon Pier Kitty Hawk Area & Dare & 5 & 0.14 \\
9 & Ft Macon State Park & Carteret & 204 & 5.66 \\
10 & Emerald Isle Public Access Area & Carteret & 48 & 1.33 \\
11 & Oregon Inlet North Shore & Dare & 357 & 9.91 \\
12 & Hatteras Inlet Beach & Hyde & 21 & 0.58 \\
13 & Access at New River Inlet Drive & Onslow & 5 & 0.14 \\
14 & Beach Access Ramp 20 & Dare & 41 & 1.14 \\
15 & Beach Access Ramp 23 & Dare & 21 & 0.58 \\
16 & Beach Access 27 & Dare & 12 & 0.33 \\
17 & Beach Access 30 & Dare & 23 & 0.64 \\
18 & Beach Access Ramp 34 & Dare & 17 & 0.47 \\
19 & Beach Access Ramp 38 & Dare & 37 & 1.03 \\
20 & New River Inlet, Topsail Island & Onslow & 143 & 3.97 \\
21 & Carolina Beach NW Extension & New Hanover & 4 & 0.11 \\
22 & Calvin Street Kill Devil Hills & Dare & 20 & 0.55 \\
23 & 1st Street Kill Devil Hills & Dare & 27 & 0.75 \\
24 & Public Access E. Gulfstream S. Nags Head & Dare & 5 & 0.14 \\
25 & Public Access E. Bonnett St Nags Head & Dare & 10 & 0.28 \\
26 & Public Access E. Forest St Nagshead & Dare & 2 & 0.06 \\
27 & Ramp 49 Frisco & Dare & 1 & 0.39 \\
28 & South Topsail Beach Bank & Pender & 0.03
\end{tabular}




\section{Empirical model}

Suppose an angler considers a number of recreation sites on each choice occasion. The individual utility from the trip decreases in trip cost and increases in trip quality following:

$$
u_{i}=v_{i}\left(y-p_{i}, q_{i}, w_{i}\right)+\varepsilon_{i}
$$

where $u$ is the individual utility function, $v$ is the nonstochastic portion of the utility function, $y$ is income, $p$ is the trip cost, $q$ is site quality, $w$ is beach width, $\varepsilon$ is the error term, and $\mathrm{i}$ is a member of $\mathrm{J}$ recreation sites, $\mathrm{j}=1, \ldots, \mathrm{i}, \ldots \mathrm{J}$. The individual chooses the site that gives the highest utility:

$$
\pi_{i}=\operatorname{Pr}\left(v_{i}+\varepsilon_{i}>v_{s}+\varepsilon_{s} \forall J \neq i\right)
$$

\section{Table 3 Pier and bridge fishing site trip frequency}

\begin{tabular}{lllrl} 
Choice & Site Name & County & Frequency & Percent \\
\hline 1 & Seaview Pier & Pender & 63 & 1.75 \\
2 & Sunset Beach Fishing Pier & Brunswick & 22 & 0.61 \\
3 & Yaupon Beach Fishing Pier & Brunswick & 31 & 0.86 \\
4 & Ocean Isle Pier & Brunswick & 4 & 0.11 \\
5 & Nags Head Fishing Pier & Dare & 216 & 5.99 \\
6 & Avalon Pier Kitty Hawk Area & Dare & 285 & 7.91 \\
7 & Bogue Inlet Fishing Pier & Carteret & 260 & 7.21 \\
8 & Frisco Pier & Dare & 70 & 1.94 \\
9 & Hatteral Fishing Pier & Dare & 55 & 1.53 \\
10 & Holden Beach Fishing Pier & Brunswick & 23 & 0.64 \\
11 & Jeanette's Ocean Fishing Pier & Dare & 7 & 0.19 \\
12 & Outer Banks Pier South Nags Head & Dare & 108 & 3.00 \\
13 & Oceanana Fishing Pier & Carteret & 31 & 0.86 \\
14 & Sportsmans Pier & Carteret & 290 & 8.05 \\
15 & Triple "S" Fishing Pier & Carteret & 137 & 3.8 \\
16 & Jolly Rogers Pier & Pender & 58 & 1.61 \\
17 & Surf City Ocena Pier & Pender & 46 & 1.28 \\
18 & Oregon Inlet Bridge & Dare & 22 & 0.61 \\
19 & Kure Beach Pier & New Hanover & 100 & 2.77 \\
20 & Long Beach Fishing Pier & Brunswick & 3 & 0.08 \\
21 & Avon Fishing Pier & Dare & 153 & 4.25 \\
22 & Carolina Beach Pier & New Hanover & 97 & 2.69
\end{tabular}


where $\pi$ is the probability that site $i$ is chosen. If the error terms are independent and identically distributed extreme value variates, then the conditional logit model results:

$$
\pi_{i}=\frac{e^{v_{i}}}{\sum_{j=1}^{J} e^{v_{j}}}
$$

The conditional logit model restricts choices according to the assumption of the independence of irrelevant alternatives (IIA). The IIA restriction forces the relative probabilities of any two choices to be independent of other changes in the choice set. For example, if a quality characteristic at site i causes a $5 \%$ decrease in the probability of visiting site $i$, then the probability of visiting each of the other $j$ sites must increase equally to sum to a $5 \%$ increase. This assumption is unrealistic if any of the $j$ sites is a better substitute for site i relative to the other sites.

The nested logit model relaxes the IIA assumption by allowing recreation sites in the same choice nest to be better substitutes than recreation sites in other nests. Choice probabilities for recreation sites within the same nest are still governed by the IIA assumption. Consider a two-level nested model. The site choice involves a choice among $M$ groups of sites or nests, $m=1, \ldots, M$. Within each nest, is a set of Jm sites, $\mathrm{j}=1, \ldots, \mathrm{Jm}$. When the nest chosen, $\mathrm{n}$, is an element in $\mathrm{M}$, the site choice, $\mathrm{i}$, is an element in $\mathrm{Jm}$ and the error term is distributed as generalized extreme value, the site selection probability in a two-level nested logit model is:

$$
\pi_{n i}=\frac{e^{v_{n i} / \theta}\left[\sum_{j=1}^{J_{n}} e^{v_{n j} / \theta}\right]^{\theta-1}}{\sum_{m=1}^{M}\left[\sum_{j=1}^{J_{m}} e^{v_{m j} / \theta}\right]^{\theta}}
$$

where the numerator of the probability is the product of the utility resulting from the choice of nest $\mathrm{n}$ and site $\mathrm{i}$ and the summation of the utilities over sites within the chosen nest $\mathrm{n}$. The denominator of the probability is the summation over the utilities of all sites within each nest summed over all nests. The dissimilarity parameter, $0<\mathrm{q}<1$, measures the degree of similarity of the sites within the nest. As the dissimilarity parameter approaches zero, the alternatives within each nest become less similar to each other when compared to sites in other nests. If the dissimilarity parameter is equal to one, the nested logit model collapses to the conditional logit model. Welfare analysis is conducted with the nested logit model by, first, specifying a functional form for the site utilities. It is typical to specify the utility function as linear:

$$
v_{n i}\left(y-p_{n i}, q_{n i}, w_{n i}\right)=\alpha\left(y-p_{n i}\right)+\beta q_{n i}+\gamma w_{n i}=\alpha y-\alpha p_{n i}+\beta q_{n i}=-\alpha p_{n i}+\beta q_{n i}+\gamma w_{n i}
$$

where $\alpha$ is the marginal utility of income. Since $\alpha y$ is a constant, it will not affect the probabilities of site choice and can be dropped from the utility function. 
The next step is to recognize that the inclusive value is the expected maximum utility from the cost and quality characteristics of the sites. The inclusive value, IV, is measured as the natural log of the summation of the nest-site choice utilities:

$$
I V(p, q, w ; \alpha, \beta, \gamma)=\ln \left(\sum_{m=1}^{M}\left[\sum_{j=1}^{J_{m}} e^{v_{m j} / \theta}\right]^{\theta}\right)
$$

Hanemann (1999) shows that the per choice occasion welfare change from a change in quality characteristics is:

$$
W T P=\frac{I V(p, q, w ; \alpha, \beta, \gamma)-I V(p, q, w-\Delta w ; \alpha, \beta, \gamma)}{\alpha}
$$

where willingness to pay, WTP, is the compensating variation measure of welfare. Haab and McConnell (2002) show that the willingness to pay for a quality change (e.g., changes in beach width) can be measured as

$$
W T P(\Delta w \mid n i)=\frac{\gamma \Delta w_{n i}}{\alpha}
$$

Willingness to pay for the elimination of a recreation site from the choice set (e.g., beach erosion that eliminates the sandy beach) is

$$
W T P(i \mid n)=\frac{\ln \left[(1-\operatorname{Pr}(i \mid n))^{\theta} \operatorname{Pr}(n)+(1-\operatorname{Pr}(n))\right]}{\alpha}
$$

where $\operatorname{Pr}(\mathrm{i} \mid \mathrm{n})$ is the unconditional probability of choosing site i given that nest $\mathrm{n}$ is chosen and $\operatorname{Pr}(\mathrm{n})$ is the unconditional probability of choosing nest $\mathrm{n}$.

These welfare measures apply for each choice occasion (i.e., trips taken by the individuals in the sample). If the number of trips taken is unaffected by the changes in beach width, then the total willingness to pay is equal to the product of the per trip willingness to pay and the average number of recreation trips, $x$. If the number of trips taken is affected by the changes in beach width, then the appropriate measure of aggregate WTP must be adjusted by the change in trips. There are several methods of linking the trip frequency model with the site selection model (Parsons et al. 1999). We employ the original approach that includes the inclusive parameter as a variable in the trip frequency model (Bockstael et al. 1987):

$$
x=x[I V(c, q, w ; \alpha, \beta, \gamma)]
$$


Where $x[$.$] is a trip frequency model. These models are typically estimated with count$ (i.e, integer) data models such as the Poisson or negative binomial models (Haab and McConnell 2002, Parsons 2003). Parsons et al. (1999) find that the linked model generates results similar to a repeated choice logit model.

Total trips under various climate change scenarios can be simulated by substitution of alternative beach width into the trip frequency model:

$$
x(\Delta)=x[I V(c, q, w-\Delta w ; \alpha, \beta, \gamma)]
$$

The total willingness to pay of a change in beach width that might affect the number of trips is aggregated over the number of trips:

$$
\operatorname{TWTP}(\Delta w)=\sum_{m=1}^{M} \sum_{j=1}^{J_{m}}\left(\left[\bar{x}_{m j}(\Delta)\right] W T P(\Delta w \mid m j)+\left[\bar{x}_{m j}-\bar{x}_{m j}(\Delta)\right] W T P(m \mid j)\right)
$$

The first component of the total willingness to pay, TWTP, is the product of the average number of trips taken with the quality change and the value of the quality change. The second component of the willingness to pay is the product of the difference in trips and the willingness to pay for a trip to a particular site.

\section{Empirical results}

We modeled the angler fishing site choice in two stages (Fig. 3). The first stage choice of shore anglers differentiates between the pier and bridge fishing mode and the beach fishing mode. In addition, we assume that anglers choose spatially between a northern trip (i.e., Outer Banks) and a southern North Carolina fishing trip. In the second stage decision,

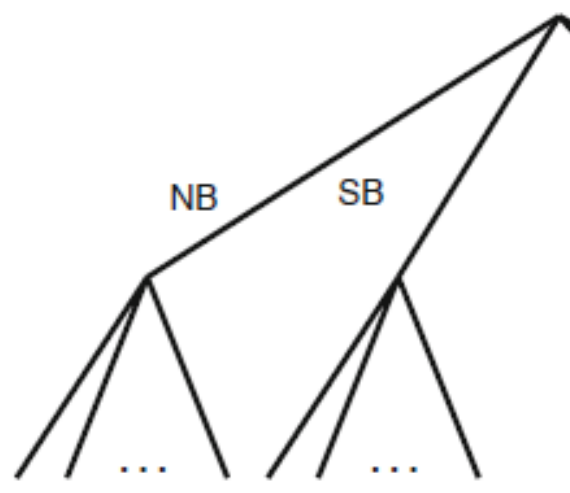

19 Sites

9 Sites

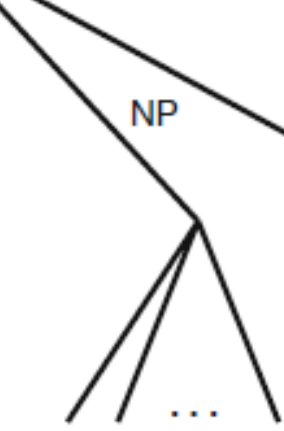

8 Sites

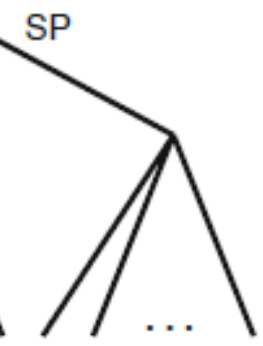

14 Sites

Fig. 3 Nested fishing mode I region / site choice model. (NP Northern Pier, SP Southern Pier, NB Northern Beach, SP Southern Beach) 
anglers choose fishing sites. The theory behind the nested logit is that anglers consider fishing sites based on the utility (i.e., satisfaction) that each site provides. Anglers will tend to choose fishing sites that provide the most utility. The nested logit exploits the empirical observation that anglers tend to choose fishing sites with relatively low travel costs and relatively high chances of fishing success. The utility function is a linear relationship among the travel costs, the hourly catch rate and beach width. The nested logit estimates the two stages of choice jointly using the full information maximum likelihood PROC MDC in SAS (Table 4).

The likelihood that an angler would choose a fishing site is negatively related to the travel cost and positively related to the historic targeted hourly catch rate. Beach width is positively related to site choice. In other words, beach anglers prefer lower costs, higher catch rates and wider beaches. Various other model specifications (e.g., including a squared width term and width plus and minus one standard deviation) were investigated to test the sensitivity of results to the simple linear specification. The simple linear specification was statistically preferred. The parameter estimate on the mode/region-specific inclusive value is between zero and one and statistically different from zero and one indicating that the nested model is appropriate.

A limitation of the nested logit model is that it holds the number of fishing trips constant. With the loss of a fishing site, anglers are assumed to substitute other sites or fishing modes. This assumption may be appropriate for many events and policies that have a minor impact on the fishing experience. However, for lost beach fishing sites and lost quality, it would not be surprising if the aggregate number of fishing trips declines. An ad-hoc, though practical, approach to estimating this effect is with a trip intensity model in which angler trips are regressed on the inclusive value, which is constructed for each angler from the parameters of the nested logit, and other individual angler characteristics. If trips are positively related to the utility of fishing, then a change in fishing conditions which lowers utility will lead to fewer trips taken.

The trip intensity model is a negative binomial model estimated with Proc GENMOD in SAS. The dependent variable in the negative binomial trip intensity model is the annual number of fishing days. The negative binomial model accounts for the integer values and the truncation of the dependent variable at a value of one. The demand model does a satisfactory job of explaining the variation in fishing days (Table 5). Shore anglers increase trips as the inclusive value (i.e., utility of fishing) increases. More intuitively, trips increase as travel costs decrease because the inclusive value is negatively related to travel costs (catch rates and width do not vary across anglers). The dispersion coefficient is statistically different from zero which suggests that the negative binomial is the appropriate model relative to the Poisson. 
Table 4 Nested random utility model (dependent variable=mode-region-site choice)

\begin{tabular}{llll} 
& Mean & Coeff. & t-ratio \\
\hline Travel Cost & 197.70 & -0.0254 & -31.92 \\
Catch rate per hour & 0.62 & 0.103 & 3.40 \\
Beach Width & 54.34 & 0.00753 & 26.47 \\
IV & 0.401 & 23.96 \\
McFadden's R & & 0.0996 & \\
Trips & 3,604 & \\
Sites & 50 & 169.68 \\
Table 5 Negative binomial participation model (dependent variable = days fished) \\
\multicolumn{3}{c}{ Coeff. } \\
Intercept & 3.512 & 33.03 \\
IV & 0.3105 & 47.29 \\
Dispersion & 1.485 & t-statistic \\
Cases & 3,604 & \\
\hline
\end{tabular}

Mean $=38.15$, standard deviation $=61.87$

\section{Willingness to pay}

A large number of WTP estimates can be developed from the model including the loss of access to fishing sites, changes in catch rates and changes in beach width. For example, the change in WTP per trip from a change in the catch rate of one fish per hour at each site is $\$ 4.04$. The change in WTP per trip from an increase in beach width of $10 \mathrm{~m}$ is $\$ 2.97$. Both results seem to be of a reasonable magnitude which lends credibility to the model.

The WTP loss resulting from reduced beach width is estimated by calculating the change in angler utility using the beach width data. Beaches with negative width, "Oregon Inlet South" and "South Topsail Beach Bank" in 2030 and 2080 and "Ocracoke Inlet Beach N. \& S." in 2080, are removed from the choice set. The mean change in WTP per trip with reduced beach width in 2030 is $\$ 8.54$ (standard deviation=0.73). The mean change in WTP per trip with reduced beach width in 2080 is $\$ 9.39$ (standard deviation=1.43).

We aggregate WTP values over 3.84 million North Carolina shore mode ocean fishing trips (personal communication, NMFS 2006). The baseline (without sea level rise) total number of trips in 2030 and 2080 is estimated as simple $50 \%$ and $100 \%$ increases in trip estimates relative to 2006, respectively. We use this simple approach for several reasons. First, Smith (2006) estimates that the NC population will increase by $50 \%$ from 2000 to 2030 and increase by $100 \%$ from 2000 to 2080 . Increases in population 
increase the size of the recreation market. Second, Milon (2000) uses the MRFSS participation data and forecasts fishing participation out to 2025. He finds that participation, measured as the percentage of the population that takes at least one marine recreational fishing trip, will decline slightly. Third, an analysis of the National Survey of Recreation and the Environment saltwater fishing participation data finds that income increases do not significantly affect North Carolina saltwater fishing participation. In light of these results, we assume that the number of trips per angler stays constant while the number of participants increases only with population, with a constant participation rate. Our estimates of future trips are significantly lower than a forecast that uses the trend line from the 1981-2006 aggregate MRFSS data to forecast trips into the future. Our simple estimate is 9\% lower in 2030 and 32\% lower in 2080 (personal communication, National Marine Fisheries Service). Therefore, our estimates of the economic effects of sea level rise on marine recreational fishing may be conservative.

Assuming that the shore fishing participation rate is constant between 2006 and 2080, aggregate annual WTP loss due to the decrease in quality associated with sea level rise is $\$ 33$ million in 2030 and $\$ 36$ million in 2080 . Assuming that the number of shore fishing participants increases by $50 \%$ between 2006 and 2030, aggregate annual WTP loss is $\$ 49$ million in 2030 . Assuming that the number of shore fishing participants increases by $100 \%$ between 2006 and 2080 , aggregate annual WTP loss is $\$ 72$ million in 2080.

Annual welfare costs from 2006-2080 due to reductions in beach width are estimated by assuming the impacts of sea level rise are equal to zero in 2006 and increase linearly to 2030 and then 2080. In order to estimate the aggregate cost we compute the present value, $P V=\sum \frac{W T P_{t}}{(1+r)^{t}}$, where $\mathrm{r}$ is the discount rate and $\mathrm{t}$ is the time period. The choice of discount rate is crucial when assessing the economic effects of climate change (Anthoff et al. 2009). Different discount rates will lead to wide-ranging present value estimates due to the long time horizon. For this exercise we use the $2 \%$ discount rate required by the U.S. Congressional Budget Office which is based on the U.S. Treasury's borrowing rate (Howe 1990). We also present the rate required by the U.S. Office of Management and Budget (7\%) for sensitivity analysis. Using a $2 \%$ discount rate, the present value of the aggregate annual WTP loss is $\$ 930$ million assuming no change in fishing participation and $\$ 1.54$ billion assuming an increase in participants (Table 6).

The negative binomial regression model is used to simulate the number of fishing days that anglers would experience with the loss of beach width. The predicted number of annual fishing days falls from 36.96 in $2005-06$ to 34.48 in 2030 , a $6.7 \%$ decrease, and to 34.17 in 2080 (another $0.8 \%$ decrease). The value of the lost trips is estimated by determining the value of lost beach sites using Eq. 9. The value of a lost beach fishing trip is $\$ 21.58$. Considering the baseline 3.84 million shore fishing trips in 2006 , a $6.7 \%$ reduction in trips is 257 thousand trips. The annual economic loss associated with the reduction in trips is \$5.6 million in 2030 with no upward trend in fishing trips. The additional annual economic loss associated with the additional $0.8 \%$ reduction in trips in 
2080 is an additional $\$ 663$ thousand with no upward trend in fishing trips. Assuming that the number of shore trips increases by $50 \%$ between 2006 and 2030 and by $100 \%$ between 2006 and 2080, aggregate WTP loss due to a reduction in trips is $\$ 8.3$ million in 2030 and an additional $\$ 4.1$ million by 2080 .

The present value of the annual aggregate WTP loss from 2006-2080 due to reductions in trips is estimated by assuming the impacts of sea level rise are equal to zero in 2006 and increase linearly to 2030 and 2080 . The present value of the WTP loss is $\$ 158$ million assuming no change in fishing participants and $\$ 265$ million assuming an increase in fishing participants. Combining the WTP losses due to reductions in beach width of existing trips and reductions in fishing trips due to reductions in beach width provides an estimate of the total shore fishing WTP loss associated with sea-level rise. The present value of the total WTP loss is $\$ 1.1$ billion assuming no change in participants and $\$ 1.8$ billion with an increase in fishing participants.

The total present value of shore fishing trips is estimated as the product of the discounted value per trip and the number of trips. Using a $2 \%$ discount rate, the present value of the total value of trips is $\$ 3.1$ billion assuming no change in participants and $\$ 4.7$ billion with an increase in fishing participants. Relative to this baseline, the total loss from sea level rise is estimated to be $35 \%$ with no change in participants and $39 \%$ with an increase in participants.

Table 6 Present value of aggregate willingness to pay loss due to sea level rise (millions of 2005 dollars): 2007-2080

\begin{tabular}{lccc} 
& Discount rate & \multicolumn{2}{l}{ Participants } \\
\cline { 4 - 4 } & & Constant & Increasing \\
\hline Beach Width & $2 \%$ & 930 & 1,539 \\
Beach Width & $7 \%$ & 209 & 324 \\
Trips & $2 \%$ & 158 & 262 \\
Trips & $7 \%$ & 35 & 56
\end{tabular}

\section{Conclusions}

In this paper, we develop estimates of the economic effects of climate change-induced sea level rise on marine recreational shore fishing in North Carolina. In addition to the choice of the discount rate and the number of participants, our results are sensitive to a number of assumptions regarding coastal erosion and decisions made implementing the travel cost method. Nevertheless, our analysis is informative for policy analysis in that it provides an order of magnitude estimate of some previously unestimated costs of climate change. We find that the welfare losses are potentially substantial, ranging up to a present value of $\$ 1.8$ billion over 75 years, 39\% of the total value, using conservative estimates of fishing participation growth and a $2 \%$ discount rate. 
Our analysis is limited in a number of ways. The impacts on shore anglers are partially muted since piers are a good substitute for fishing from the beach. However, pier fishing in North Carolina is becoming more limited as coastal property values rise. Some of the piers in the 2005 data were not available as substitute fishing sites in 2006. Other piers are in jeopardy. Also, boat anglers might be affected by sea-level rise if marinas must be relocated. Our analysis does not include these impacts.

Second, our analysis focuses on only one aspect of climate change: sea level rise. Changes in temperature and precipitation might also impact shore fishing behavior. Other climate-related changes could include changes in fish stocks and population shifts to less or more desirable target species. These additional impacts could increase or decrease our estimates.

Third, a limitation of the MRFSS data is that they include information on recreational participants only. Another potential impact of sea-level rise is its negative effect on participation. Marine recreational shore anglers may choose another recreation activity, such as freshwater fishing, if shore based fishing becomes unavailable. To the extent that substitute activities are available and acceptable to shore anglers, we overestimate the impacts of sea-level rise. These extensions are left for future research.

Finally, this study helps to identify one of the benefits of climate change mitigation policy (or the costs or inaction) that was previously a knowledge gap. Focusing on the nonmarket effects is especially important because the market effects of climate change policy can be measured with observable parts of the economy such as market prices and quantities. The nonmarket effects of climate change mitigation policy are less well known because they occur outside of markets and are more difficult to estimate. Future research should consider other unexplored nonmarket economic effects of climate change.

Acknowledgement The authors thank Joel Smith, David Chapman, Michael Hanemann, Sasha Mackler and several anonymous reviewers for guidance and comments on this research. This research was supported by the National Commission on Energy Policy and the University of North Carolina Research Competitiveness Fund. 


\section{References}

Ahn SJ, DeSteiguer JE, Palmquist RB, Holmes TP (2000) Economic analysis of the potential impact of climate change on recreational trout fishing in the Southern Appalachian Mountains: an application of a nested multinomial logit model. Clim Change 45:493-509

Anthoff D, Tol RSJ, Yohe GW (2009) Discounting for climate change. Economics: The Open-AccessOpen- Assessment E-Journal 3:2009-24

Bockstael NE, Hanemann WM, Kling CL (1987) Estimating the value of water quality improvements in a recreational demand framework. Water Resour. Res. 23(5):951-960

Crowell M, Douglas BC, Leatherman SP (1997) On forecasting future U.S. shoreline positions: a test of algorithms. J. Coastal Res. 13(4):1245-1255

Englin J, Moeltner K (2004) The value of snowfall to skiers and boarders. Environ Resource Econ 29:123-136

Gentner B, Price M, Steinback S (2001) Marine Angler Expenditures in the Southeast Region, 1999, NOAA Technical Memorandum NMFS-F/SPO-48, August.

Haab TC, McConnell KE (2002) Valuing environmental and natural resources: the econometrics of nonmarket valuation. Edward Elgar, Northampton

Haab TC, Whitehead JC, McConnell T (2000) The economic value of marine recreational fishing in the Southeast United States: 1997 Southeast economic data analysis. Final Report for NMFS Contract No. 40WCNF802079, National Marine Fisheries Service, Southeast Regional Office, St. Petersburg, FL.

Hanemann WM (1999) Welfare Analysis with Discrete Choice Models, Chapter 2 in Valuing Recreation and the Environment: Revealed Preference Methods in Theory and Practice, ed. by Joseph A. Herriges and Catherine L. Kling, Edward Elgar Publishing.

Hellerstein D, Woo D, McCollum D, Donnelly D (1993) ZIPFIP: a Zip and FIPS database. Washington DC, Department of Agriculture, ERS-RTD

Howe CW (1990) The social discount rate. J Environ Econ Manage 18(2):S1-S2

Intergovernmental Panel on Climate Change (2007) Climate Change 2007: The Physical Science Basis. Summary for Policymakers: Contribution of Working Group I to the Fourth Assessment Report of the Intergovernmental Panel on Climate Change. http://www.ipcc.ch/SPM2feb07.pdf. 
Loomis J, Crespi J (1999) Estimated Effects of Climate Change on Selected Outdoor Recreation Activities in the United States. Chapter 11 in The Impact of Climate Change on the United States Economy, Robert Mendelsohn and James E. Neumann (eds) Cambridge University Press, pp. 289-314.

McConnell KE (1977) Congestion and willingness to pay: a study of beach use. Land Econ 53(2):185-195

McConnell KE, Strand IE (1999) Overnight Trip Choice for Marine Anglers. Report on NMFS contract number 40ANF804203, August 8.

Mendelsohn R, Markowski M (1999) The impact of climate change on outdoor recreation," Chapter 10 in The impact of climate change on the United States Economy, Robert Mendelsohn and James E. Neumann (eds) Cambridge University Press, pp. 267-288.

Mendelsohn R, Neumann JE (eds) (1999) The Impact of Climate Change on the United States Economy, Cambridge University Press, pp. 267-288.

Milon JW (2000) Current and future participation in marine recreational fishing in the Southeast U.S. Region. NOAA technical memorandum NMFS-F/SPO-44. National Marine Fisheries Service (2006) Fisheries Statistics Division, http://www.st.nmfs.noaa.gov/st1/index.html.

Parsons GR (2003) The travel cost model. In: Champ PA, Boyle KJ, Brown TC (eds) A primer on nonmarket valuation. Kluwer, London

Parsons GR, Jakus PM, Tomasi T (1999) A comparison of welfare estimates from four models for linking seasonal recreational trips to multinomial logit models of site choice. $\mathrm{J}$ Environ Econ Manage 38:143- 157

Pendleton LH, Mendelsohn R (1998) Estimating the economic impact of climate change on the freshwater sportsfisheries of the Northeastern U.S. Land Econ 74(4):483-496

Richardson RB, Loomis JB (2004) Adaptive recreation planning and climate change: a contingent visitation approach. Ecol Econ 50:83-99

Shaw WD, Loomis JB (2008) Frameworks for analyzing the economic effects of climate change on outdoor recreation. Climate Res 36:259-269

Silberman J, Klock M (1988) The recreation benefits of beach nourishment. Ocean and Shorel Manag 11:73-90

Smith J (2006) Memorandum: scenarios for the national commission on energy policy, August 1. 
Smith VK, Kaoru Y (1990) What have we learned since hotelling's letter?: A metaanalysis. Econ Lett 32 (3):277-281

Zhang K, Douglas B, Leatherman S (2004) Global warming and coastal erosion. Clim Change 64(1-2):41-58 18 